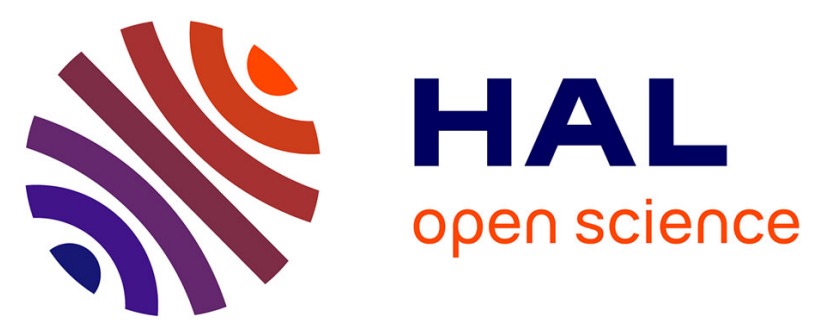

\title{
Low host specificity and broad geographical ranges in a community of parasitic non-pollinating fig wasps (Sycoryctinae; Chalcidoidea)
}

Xiaoxia Deng, Lianfu Chen, Enwei Tian, Dayong Zhang, Tanming Wattana, Hui Yu, Finn Kjellberg, Simon T Segar

\section{To cite this version:}

Xiaoxia Deng, Lianfu Chen, Enwei Tian, Dayong Zhang, Tanming Wattana, et al.. Low host specificity and broad geographical ranges in a community of parasitic non-pollinating fig wasps (Sycoryctinae; Chalcidoidea). Journal of Animal Ecology, 2021, 90 (7), pp.1678-1690. 10.1111/1365-2656.13483 . hal-03411300

\author{
HAL Id: hal-03411300 \\ https://hal.science/hal-03411300
}

Submitted on 2 Nov 2021

HAL is a multi-disciplinary open access archive for the deposit and dissemination of scientific research documents, whether they are published or not. The documents may come from teaching and research institutions in France or abroad, or from public or private research centers.
L'archive ouverte pluridisciplinaire HAL, est destinée au dépôt et à la diffusion de documents scientifiques de niveau recherche, publiés ou non, émanant des établissements d'enseignement et de recherche français ou étrangers, des laboratoires publics ou privés. 
DOI: $10.1111 / 1365-2656.13483$

Low host specificity and broad geographic ranges in a community of parasitic nonpollinating fig wasps (Sycoryctinae; Chalcidoidea)

Short running title: Range wide population genetics of parasitic fig wasps

DENG, Xiaoxia**1,2,3, CHEN Lianfu**1,2,3 ${ }^{*}$ TIAN Enwei ${ }^{1}$, ZHANG Dayong ${ }^{4}$, WATTANA 5 Tanming $^{1}$, YU Hui ${ }^{* 1,2,3}$, KJELLBERG Finn ${ }^{2}$, SEGAR, Simon T. ${ }^{3}$

* Author for correspondence

** these authors contributed equally.

${ }^{1}$ Key Laboratory of Plant Resource Conservation and Sustainable Utilization, South China Botanical Garden, The Chinese Academy of Sciences, Guangzhou 510650, China

${ }^{2}$ Centre for Plant Ecology, CAS Core Botanical Gardens, Guangzhou 510650, China

${ }^{3}$ Southern Marine Science and Engineering Guangdong Laboratory (Guangzhou), Guangzhou 511458

${ }^{4}$ State Key Laboratory of Earth Surface Processes and Resource Ecology and MOE Key Laboratory for Biodiversity Science and Ecological Engineering, College of Life Sciences, Beijing Normal University, Beijing, China

${ }^{1}$ Queen Sirikit Botanic Garden, Chiang Mai, Thailand

${ }^{2}$ CEFE, Univ Montpellier, CNRS, Univ Paul Valéry Montpellier, EPHE, IRD, France

${ }^{3}$ Agriculture and Environment Department, Harper Adams University, Newport, Shropshire, United Kingdom. 


\section{Abstract}

Plants, phytophagous insects and their parasitoids form the most diverse communities of macroscopic organisms on earth. Using molecular approaches, we document the composition and host specificity of a multi-trophic insect community associated with Ficus hirta throughout its $3500 \mathrm{~km}$ range across continental and insular Asia. We test expectations derived from population genetic and community studies. We find low host specificity in two genera of non-pollinating fig wasps. Functional community structure is largely conserved across the range of the host fig, despite limited correspondence between the ranges of nonpollinator and pollinator species. While nine pollinators are associated with Ficus hirta, the two non-pollinator tribes developing in its figs each contained only four species. Contrary to predictions we find stronger isolation by distance in non-pollinators than pollinators. Long lived non-pollinators may disperse more gradually and be less reliant on infrequent longdistance dispersal by wind currents. Segregation among non-pollinating species across their range is suggestive of competitive exclusion and we propose that this may be a result of increased levels of local adaptation and moderate, but regular, rates of dispersal. Our findings provide one more example of lack of strict codiversification in the geographic diversification of plant associated insect-communities.

45 Key words: Beta-diversity, community assembly, parasitoid, population genetics, mutualism. 


\section{Introduction}

Herbivorous insects and their parasitoids make up over $50 \%$ of all described insect species (Price, 2002). In addition to being of high economic relevance both trophic levels contribute 50 substantially to biodiversity and ecosystem function (B. A. Hawkins, Cornell, \& Hochberg, 1997). Herbivores and parasitoids are also model systems for studying community assembly and coevolution. One of the most fundamental questions in ecology is how multitrophic communities and networks assemble across time and space. Under the expectation of classical cospeciation, entire communities might codiversify such that interactions are inherited across speciation events resulting in predictable and replicated community structure. Widespread evidence suggests that such a process is rare and that coevolution in most networks is diffuse and context dependent (Thompson, 1994), but still a key driver of network structure (Segar et al., 2020). It is, therefore, necessary to study species across their entire range to fully understand the process behind community patterns. More generally, geographical variation in the specialisation of host-parasitoid networks can be driven by contrasting patterns of beta-diversity among trophic levels, making it important to quantify both local and regional network structure (Galiana, Hawkins, \& Montoya, 2019).

A major determinant of parasitoid network structure is host specificity because this will determine the number of trophic links formed. Indeed, Hawkins (1994) points to host concealment as a major predictor of parasitoid specificity: concealed hosts are predicted to host generalist ectoparasitic idiobionts and exposed hosts specialist endoparasitic koinobionts. In natural communities of herbivores, parasitoids have been found to be hostspecific (an average of 1.8 hosts in a New Guinean caterpillar community (Hrcek, Miller, Whitfield, Shima, \& Novotny, 2013)), but this can vary in contrast to expectations between 70 host guilds with parasitoids of semi-concealed hosts being the most host specific. Parasitoids of the miner guild can also be host specific (an average of 2.8 hosts in one Belizean web) but 
vary in this degree (Leppänen, Altenhofer, Liston, \& Nyman, 2013; Lewis et al., 2002). Evidence for 'Host Associated Differentiation' (the evolution of specialists across host genotypes) suggests that parasitoids of highly concealed galling insects (Nicholls,

75 Schönrogge, Preuss, \& Stone, 2018; Stireman, Nason, Heard, \& Seehawer, 2006) can even be amongst the most host specific of insects. However, realised host breadth of parasitoids can be determined by multiple additional factors including evolutionary history (of both host and parasitoid), host abundance and geographical range (B. A. Hawkins, 1994).

Prevailing evidence points to low levels of ecologically equivalent species in herbivores (Butterill \& Novotny, 2015; Hrcek et al., 2013; Vojtech Novotny et al., 2012) but a high frequency of morphologically highly similar (cryptic) species among their parasitoids (Li et al., 2010; Smith et al., 2008; Smith, Woodley, Janzen, Hallwachs, \& Hebert, 2006) which only in some cases stems from host associated differentiation (Hernández-López et al., 2012). Indeed, cryptic species are common in parasitoid networks and their inclusion is crucial to 85 inform our understanding of network structure and turnover (Hrcek \& Godfray, 2015; Van Veen, Müller, Pell, \& Godfray, 2008).

Meso-diverse insect communities in enclosed microcosms, such as those associated with oak (Quercus) galls, have become model systems for studying host specificity (Nicholls et al., 2018) and community assembly (Bunnefeld, Hearn, Stone, \& Lohse, 2018) due to their replicated nature and intercontinental distributions. The current population genetic structure among Quercus species and their associated insect fauna has been highly dependent on glacial cycles (Stone et al., 2012). The multi-trophic wasp communities associated with plants of the genus Ficus have great potential to serve as a complimentary system to gall wasps. Pollinating fig wasps (Agaonidae, Chalcidoidea) co-exist with members of several 
other chalcid (sub) families. Some fig wasps, including the pollinating wasps, gall fig ovules, other fig wasps parasitise pollinators and/or other gall formers (as parasitoids or cleptoparasites) while a third trophic level of hyper-parasitoids can also be present (J. M Cook \& Rasplus, 2003). Being largely tropical in distribution they offer a tractable counterpoint to the temperate oak galling communities. For example, functional community structure has been shown to be retained across the paleotropics, despite turnover of every species in the community of the canopy hemi-epiphyte F. benjamina (Darwell, Segar, \& Cook, 2018).

While figs and their pollinators provide one of the strongest examples of codiversification on a global scale (Cruaud et al., 2012), regional and local dynamics can demonstrate multiple trajectories. Accumulating evidence for multiple pollinators per host fig and even pollinator sharing is emerging (J. M Cook \& Segar, 2010) with recent examples demonstrating both continuity (Bain et al., 2016) and turnover in pollinator species over islands (Rodriguez et al., 2017) continents (Yu et al., 2019) and elevational gradients (Souto-Vilarós et al., 2019). Our increased understanding of speciation dynamics in pollinators has also shed more light on 110 their diversification. For instance, the pollinators associated with small dioecious hosts are thought to be particularly prone to genetic isolation due to their limited dispersal capabilities when compared to the above canopy dispersers associated with monoecious fig species (Ahmed, Compton, Butlin, \& Gilmartin, 2009; Compton, Ellwood, Davis, \& Welch, 2000; Harrison \& Rasplus, 2006; Yu et al., 2019). The concept of high pollinator host specificity, 115 however, has survived scrutiny in most cases.

The discovery of multiple pollinators per host has often been driven by molecular evidence (Darwell, Al-Beidh, \& Cook, 2014; Molbo, 2003; e.g. Yu et al., 2019) and has gradually become reconciled with a 'split-and-sort' mechanisms for diversification (J. M Cook \& 
Segar, 2010). Diversification dynamics of parasitoids are often linked to those of their hosts (Forister \& Feldman, 2011). Broad scale studies (at the level of the Ficus section) demonstrate congruence between host, pollinator and non-pollinator phylogenies for African fig species (Jousselin et al., 2008). Putative pollinator cleptoparasites in the genus Philotrypesis (Joseph, 1958) and two lineages of Otitesella ("uluzi" and "sesquinianellata"), one a galler the other a cleptoparasite of the galler (Segar, Pereira, Compton, \& Cook, 2013, Figure 4) all showed high levels of host specificity. Both codiversification and host tracking are likely to have occurred throughout the diversification of the parasitoid fig wasps (Segar, Lopez-Vaamonde, Rasplus, \& Cook, 2012). Within this general picture of host tree specialists, several species of neotropical Idarnes wasps, including gallers and cleptoparasites (Farache et al., 2018) and a few African parasitoid species of genus Arachonia (McLeish, Beukman, van Noort, \& Wossler, 2012) are generalists, developing in the figs of several local Ficus species.

Our knowledge at finer scales is more limited, and to date only two studies have addressed the phylogeography and population genetics of non-pollinating fig wasps. Wide ranging fig species, for example the Australian Ficus rubiginosa, are associated with distinct species of non-pollinators throughout their range (Darwell \& Cook, 2017). Ficus rubiginosa hosts two parapatric species of Sycoscapter 'short' and Philotrypesis 'black'. Population genetic data from the whole range (Sutton, Riegler, \& Cook, 2016) reveals that another species, Sycoscapter 'long', demonstrates higher levels of population connectivity and/or higher levels of dispersal than in one pollinating wasp, which has a disjunct distribution (but see Kjellberg \& Proffit, 2016). 
Expectations and predictions. Here we conduct extensive sampling of the wasp community associated with the small shrub, F. hirta. Previous genetic data (Yu et al., 2019) have shown that with nine parapatric species it has the largest set of pollinators reported to date for any Ficus species. We connect this large number with the small size of the plant which may lead to localized wasp dispersal in comparison to the large strangling Ficus species, and with the seemingly elevated rate of speciation in pollinating fig wasps in comparison to fig trees (Moe, Clement, \& Weiblen, 2012). We use a range of genetic markers to establish the taxonomic equivalence of this spatially structured genetic differentiation and test the hypothesis of high connectivity between populations and/or high levels of dispersal in nonpollinating fig wasps. According to existing evidence from a single other gall/parasitoid wasp community (Sutton et al., 2016), we expect lower species diversity and turnover within parasitic fig wasps than for the pollinators, with parasites capable of utilizing most members of the pollinating wasp complex as hosts. Due to high dispersal ability and a resilience to founder effects (conferred by the limited necessity for outbred males) we expect that species ranges of parasites will not be shaped by historical contingencies but rather by inter-specific competition and species' ecological traits. Following on from range disparities and reduced parasite specificity we predict that pair-wise comparisons across sites will reveal multiple examples of parasites spread across several pollinator hosts.

160 Further, in systems presenting a linear distribution (as is the case for F. rubiginosa) different species may abut on the same ecological barrier, incidentally leading to statistical association between parasites and between parasites and hosts. Such incidental correlations are expected to be less frequent in systems presenting two-dimensional distributions (as is the case for $F$. hirta), as ecological obstacles and ecological gradients are more diversified and different 
species groups may respond differently to these factors. At the community scale we expect conserved ecological function throughout the species' range (as appears to be the case in other fig-wasp systems), with the same niches existing and being filled throughout the range of $F$. hirta. This is driven by an underlying expectation that fig wasp communities should be generally saturated and structured largely by competition for limited resources. Indeed, published data suggests that while not saturated at the individual tree-crop level, fig-wasp communities are saturated when several crops are sampled more widely (Compton \& Hawkins, 1992; B. A. Hawkins \& Compton, 1992), in other words there is saturation at the regional level.

\section{Methods}

\section{(a) Study species}

Ficus hirta Vahl is a shrub of secondary vegetation (Fig. S1). Its distribution extends from the island of Java in the south to China in the north and westwards into northeast India and Nepal (Yu et al., 2019). Ficus hirta is pollinated by the host specific species complex of Valisia javana Mayr (Agaonidae, Chalcidoidea, Hymenoptera) (Yu et al., 2019). Pollinating wasps enter the fig (a closed urn-shaped receptacle) pollinate and oviposit in flowers.

Three non-pollinating chalcid fig-wasp species have been reported from $F$. hirta (Yu, Liang, Tian, Zheng, \& Kjellberg, 2018). Philotrypesis josephi and Sycoscapter hirticola in northeast India (Nair, Abdurahiman, \& Joseph, 1981) and Sycoryctes simplex in Java (Mayr, 1885). Philotrypesis (tribe Philotrypesini), Sycoscapter and Sycoryctes (tribe Sycoryctini) are monophyletic genera belonging to the subfamily Sycoryctinae (Pteromalidae) (Segar et al., 2012). They oviposit into ovaries containing Valisia larvae by inserting their long ovipositor through the fig wall. Philotrypesis are cleptoparasites while Sycoryctini are parasitoids 
(Conchou, Ciminera, Hossaert-McKey, \& Kjellberg, 2014). Philotrypesis, Sycoryctini, and pollinating Valisia are morphologically remarkably different (Fig. S1). Offspring of fig wasps mate in the fig, often between siblings, before dispersal from their natal fig, a feature that facilitates the initial establishment of rare colonizers (Yu et al., 2019).

\section{(b) Sampling}

Samples were collected from South China to Java (Supporting Information Table S1). Wasp collection protocols follow (Yu et al., 2019). Spatial structuring has been investigated for the 195 pollinators of F. hirta, Valisia spp. (Yu et al., 2019) and microsatellite data and cytochrome c oxidase I (COI) data have been obtained for Philotrypesis and Sycoscapter for samples from SouthEast China (Yu et al., 2018). We sampled representatives of each fig wasp species emerging from individual figs at each location, however we did not record complete fig contents or individual fig level occurrence data at all sites.

\section{(c) Gene sequence data}

Cytoplasmic Cytochrome b (Cytb) was sequenced as preliminary results gave inconsistent results for COI. Cytb sequences were obtained, generally for a single wasp per fig, for a total of 124 Philotrypesis from 18 sites and 76 Sycoryctini from 13 sites (Table S1). We sequenced the ITS2 gene for a total of 133 individuals from 15 sites for Philotrypesis and 54 individuals from 11 sites for Sycoryctini (Table S1). Molecular procedures were the same as in Yu et al. (Yu et al., 2018), except for Cytb amplification (see Table S2). Sequences were aligned as in Yu et al. (Yu et al., 2018). A 628 fragment of the Cytb gene and a $180 \mathrm{bp}$ fragment of the ITS2 gene were sequenced for Philotrypesis, while for the Sycoryctini the fragment lengths were 652 and 234 bp respectively.

210 The within genus phylogenetic positions of Philotrypesis, Sycoscapter and Sycoryctes species associated with Ficus section Eriosycea has not been ascertained. Therefore, we used our 
Sycoryctini samples as an outgroup of our Philotrypesis and conversely. Maximum likelihood trees were constructed using MEGA 6.0 (Tamura, Stecher, Peterson, Filipski, \& Kumar, 2013) for Cytb and ITS2 separately, and node supports were assessed based on 2000

215 bootstrap replicates. We calculated Kimura-2-parameter (K2P) distances for Cytb haplotypes and ITS2 between all individuals and within and between clades evidenced by the Maximum Likelihood tree, using MEGA 6.0.

\section{(d) Microsatellite data}

For Philotrypesis, 262 individuals, each from a different fig, were genotyped at 6 unlinked microsatellite loci. For Sycoryctini, 203 individuals, each from a different fig, were genotyped at 7 unlinked microsatellite loci. Molecular techniques follow Yu et al. (2018). Classical indices of genetic diversity were estimated using GenALEx 6.1 (Peakall \& Smouse, 2006). $F_{\text {IS }}$ values were calculated separately for each location. To provide a global representation of the data, we performed a factorial correspondence analysis as implemented in GENETIX (Belkhir, Borsa, Chikhi, Raufaste, \& Bonhomme, 1996). We used Bayesian clustering to assign multilocus microsatellite genotypes to clusters using STRUCTURE 2.2 (Pritchard, Stephens, \& Donnelly, 2000). The admixture ancestry and correlated allele frequencies model was used with three independent runs each of 500,000 MCMC iterations and 500,000 burn-in steps. We ran STRUCTURE varying K (the number of clusters) from 2 to 13 for Philotrypesis and for Sycoscapter-Sycoryctes.

\section{(e) Co-occurrence analysis}

We analysed the co-occurrence i) of species across sites, ii) between Philotrypesis and Sycoscapter and iii) between hosts and parasites. First, we plotted the occurrences of the different species on a map and made visual comparisons of the differences in the range limits 
between the species groups. Second, we constructed co-occurrence matrices for each species of each genus for all sites from which they were recorded (e.g. a 9 x 32 matrix for Valisia) and tested for aggregation or segregation by comparing the observed V-ratio (Variance ratio; mean pairwise covariance in association) to the distribution obtained from a set of 1,000 randomised matrices created by shuffling matrix fill (retaining row sums and allowing column totals to vary randomly and equiprobably). We discarded 500 randomisations as 'burnin'. We implemented this analysis using co-occurrence null models in the R package 'EcoSimR'(Gotelli, Hart, \& Ellison, 2015) by setting the metric to "V-ratio" and the algorithm to "Sim 2". We repeated this analysis for a matrix of coocurrence between Philotrypesis species and Sycoscapter species.

245 Third, we calculated the observed Czekanowski niche overlap index for Philotrypesis and Valisia species (a 4 x 9 matrix) and all Sycoscapter and Valisia species (a 3 x 9 matrix). The observed niche overlap index was compared to a distribution obtained from 1,000 randomised matrices created by shuffling matrix fill generated by reshuffling row values obtaining the observed number of interactions per species. We use only binary and not 250 abundance-based data. This analysis was also implemented in $\mathrm{R}$ using the package

'EcosimR' by running niche overlap null models, we used the Czekanowski and RA3 algorithm.

\section{Results}

Sequence data. The geographic distribution of the different haplotypes and associated 255 diversity parameters are given in Tables S2-S5. A Cytb maximum likelihood tree separated the non-pollinating wasps into 4 clades of Philotrypesis and 4 clades of Sycoryctini (Fig 1). Individuals originating from locations monomorphic for Philotrypesis or Sycoryctini Cytb clades were sequenced for ITS2. Each of the 7 sequenced Cytb clades was monomorphic for ITS2, presenting a distinctive haplotype (Fig. S2). The distribution of K2P distances within 
and among clades shows low within clade and large between clade distances for both Cytb and ITS2 (Tables S6-S7). The cumulative distribution of K2P distances for Cytb presents a marked barcoding gap between clades for both Philotrypesis and Sycoryctini (Fig. 2). Therefore, in the following, we will accept each clade as a separate species. We made the conservative choice of considering Philotrypesis samples from Sand as belonging to sp2 pending deeper sequencing. Genetic distances were smaller between Philotrypesis species than between Sycoryctini species (Fig. 1, S6-S7). Among all the data we have only one case where Philotrypesis species co-occurred in a single location while there was no cooccurrence of Sycoryctini species (Tables S2-S5). The Sycoryctini sequences from Java are highly divergent for both Cytb and ITS2 (Tables S6-S7). Morphological inspection showed that samples from Java belonged to genus Sycoryctes while samples from the continent belonged to genus Sycoscapter as currently circumscribed (Segar et al., 2012). Critical inspection of the description of Sycoscapter hirticola (Nair et al., 1981) confirmed assignment to genus.

Microsatellite data. Diversity indices are given in Table S8-S9. For Philotrypesis there was too much variation within species and too little variation among species to allow clear species separation (Fig. S3), while factorial correspondence analysis confirmed the differentiation between species in Sycoryctini (Fig. S4). Four genotypes from location Xi grouped with sp1 genotypes while 3 genotypes grouped with sp2 genotypes (Fig. S4). One genotype from Java came out with sp2 genotypes. Bayesian assignment to cluster gave the same insights as the correspondence analysis (Fig. S5-S6). For Sycoscapter, the presence in location Xi of both sp1 and sp2, and the presence of an individual of sp2 on Java was supported by the Bayesian assignment. 
Pollinators presented higher $F_{\text {IS }}$ values than Philotrypesis and Sycoryctini demonstrating more frequent brother-sister mating (Fig. S7). Sample sizes and distances among locations allowed investigating genetic isolation by distance (IBD) for Valisia spp 1 and 2, Philotrypesis spp. 1, 2, 4, and Sycoscapter sp1. In Valisia there was no IBD, but differentiation within sp1 between Hainan island, southeast China and Vietnam (Tian et al., 2015). IBD was present in Philotrypesis and Sycoscapter, except for Philotrypesis sp4 (Fig. S8).

290 Host-specificity and co-occurrence. The geographic distributions of the different species are shown in Fig. 3. The limits of the species distributions for the three types of wasps are visually different. For instance, the distribution of Valisia sp1 was established by sequencing 176 individuals for COI or for ITS2. In all locations where Valisia sp 1 was found, not a single sequence from any other Valisia species was found. Reciprocally, locations where Valisia sp1 was not found were established by sequencing 358 individuals either for COI or for ITS2. The distribution of Valisia sp1 was totally cohesive, and formed one block. Philotrypesis sp 1 was found in locations alongside Valisia sp1 (118 individuals of Philotrypesis sp1 sequenced either for CytB or for ITS2) and in locations where Valisia sp1 was not present (44 individuals of Philotrypesis sp1 sequenced either for CytB or for ITS2). 300 In Fig. 3, it can be seen that Philotrypesis sp4 uses Valisia sp6 in DAL and Valisia sp5 in SNP while Sycoscapter sp2 uses Valisia sp2 in QMS, Tai and likely CS vs. Valisia sp6/7 in Wu and Valisia sp7 in $\mathrm{CH}$.

As well as Valisia, both Philotrypesis and Sycoscapter segregated across sites (Table 1), such that the entire geographic range was divided into largely non-overlapping blocks occupied by a single species for each genus. Our co-occurrence analysis provides statistical support for this striking pattern presented in Figure 3 and outlined above. It is clear that the geographic limits of the species belonging to the two tribes of parasites do not correspond (the mean and 
simulated mean are not statistically different, Table 1). In other words, there is no broad congruence between species ranges among members of different genera. Furthermore, there is no niche partitioning between either Sycoscapter or Philotrypesis across their Valisia hosts (Czekanowski niche overlap is no different from random in either case, Table 1). Neither parasite genus shows greater levels of specialisation than expected by chance.

\section{Discussion}

While at least eight species of Valisia are associated with Ficus hirta throughout its range, we found four species of Philotrypesis, three species of Sycoscapter and one species of Sycoryctes. Our expectation of lower parasite diversity and limited host-specificity was confirmed. Philotrypesis sp1 parasitizes at least four species of the pollinating Valisia and Sycoscapter sp2 at least two species of Valisia. These parasitic wasp species are not specialists of host insect species. Ultimately, direct confirmation of host associations will only be obtained by sequencing gall content to determine the host-parasite association present in individual galls (e.g. Sow et al., 2019). Do non-pollinators exist locally but fail to develop, for example? Nevertheless, the non-overlapping distributions of pollinator species gives strength to our correlative conclusion. It is also important to note here that our sampling design did not allow for detailed (e.g. at the level of the individual fig) pair-wise comparisons of co-occurrence across fig wasp species.

Within most parasitic species we found evidence for genetic isolation by distance. Such a pattern of well delimited sister taxa displaying within species isolation by distance suggests an older colonisation of the range by extant parasite species or more limited dispersal than in the sole other non-pollinating fig wasp for which genetic data is available, a Sycoscapter associated with $F$. rubiginosa (Sutton et al., 2016). An alternative explanation is lower population density in the parasites than in the pollinators of Ficus hirta. However, there is only a limited difference in density between the two groups, which is probably not sufficient 
to explain the lack of IBD among pollinator populations coupled with strong IBD among parasite populations. Indeed, the slope of genetic differentiation is predicted to be simply inversely proportional to density, all other factors remaining constant (Rousset, 1997). The difference may relate to differences in fruiting phenology and distribution between Ficus hirta, a small dioecious shrub (continuous fruiting, growing in patches) and $F$. rubiginosa, a monoecious hemiepiphytic figs (synchronised crop on a tree, more dispersed individuals). Several of the Sycoryctine species studied here had larger geographical ranges than pollinators. For example, Philotrypesis sp 1 occurs from southern China to southern Thailand. Competitive exclusion could be a major driver in conjunction with some ecological differentiation of the parapatric distribution across sites within Philotrypesis and Sycoscapter. Indeed, the geographic distributions of diversity do not appear to be the same for each trophic group, with little correspondence seen between the ranges of Philotrypesis and Sycoscapter, and between either and Valisia. Climatic modelling would outline the role of environmental gradients versus competition, but the evidence presented here suggests that they are not the sole drivers of species distributions. While host associated differentiation is largely absent at higher trophic levels some parasites are restricted to single pollinator species, possibly because of their restricted range. The northern populations of $F$. hirta that host the more restricted Philotrypesis sp3 are phenotypically distinct and produce larger figs with thick walls (Yu et al., 2018). Perhaps the observed pattern is contingent on encounter frequency and asymmetric coevolution across trophic levels (Lapchin, 2002; diffuse coevolution). Finally, while the community of fig wasps associated with Ficus hirta is not diverse, the community structure recorded here (one pollinator, one cleptoparasite and one parasitoid) is largely conserved across the host range. This is in line with our expectations derived from other fig-wasp systems. Indeed, while Hawkins and Compton (1992) stressed a lack of saturation in fig wasp communities reared from individual crops, their extensive data set 
showed that both community structure and species richness remain constant for several Ficus sampled at a regional scale.

Sympatric, congeneric fig wasps in the same trophic guild tend to diverge in ovipositor length which is a proxy for fig development stage at oviposition (Segar, Dunn, Darwell, \& Cook, 2014; Weiblen \& Bush, 2002). This divergence is highly suggestive of divergent selection driven by competition on a shared host. In our study, sister species are largely allopatric reflecting a situation of competitive exclusion. Certainly, the congeneric individuals studied here are largely similar with respect to ovipositor length (apart from Philotrypesis sp3.) and hard to distinguish morphologically. More detailed morphological appraisal of each molecular entity would certainly be highly valuable for determining potential niche overlap. In a similar vein formal tests of phylogenetic congruence between these various taxonomic groups would be an important next step.

Despite being absent in high canopy sampling efforts (Harrison, 2003) the single species of non-pollinating fig wasp studied to date appears to be a reasonable disperser (Sutton et al., 2016). Sutton et al. (Sutton et al., 2016) report no or almost no IBD in a wide ranging Sycoscapter wasp. A general point might be the longevity of these wasps, known to live for as long as 35 days when fed sugar water (Compton, Rasplus, \& Ware, 1994; Joseph, 1958). In contrast to non-feeding pollinators and other wasps that enter monoecious figs and which disperse by wind, externally ovipositing wasps can wait for suitable clutches to become locally available. Gradual, but regular, inter-generational dispersal of these generalist parasitoids is likely given their strategy of laying small clutches of offspring across multiple figs (James M. Cook, Reuter, Moore, \& West, 2017). We might expect broad geographic ranges across parasitoid and cleptoparasitic fig wasps in general. Among the species studied 
here, some Philotrypesis species have remarkable ranges, but display higher levels of IBD than Valisia pollinators. These lines of evidence suggest a long-term host association between non-pollinating fig wasps and $F$. hirta and moderate levels of dispersal in these 'slow' wasps (Venkateswaran, Shrivastava, Kumble, \& Borges, 2017), or lower densities. Furthermore, Ficus hirta is a dioecious species with a clumped distribution in the landscape, a population structure that is likely to offset some long distance dispersal in wasps (Kjellberg \& Proffit, 2016). We suggest that strong gene flow in pollinating wasps, offset by a degree of local dispersal and in combination with limited phenotypic variation in $F$. hirta, will result in multiple phenotypically homogeneous pollinator species. Each species will be easily excluded by another species at its margins. In contrast, parasites display clinal genetic variation, likely reflecting local adaptation, and are hence more resistant to competition at the limits of their range.

\section{A generalized pattern of geographic species turnover in fig-wasp community}

The geographic variation of associated communities of fig wasps specialised on a single Ficus host have now been investigated using molecular markers for two Ficus species (Darwell et al., 2014; Darwell \& Cook, 2017; Yu et al., 2018; this study, 2019). In both cases, the wasps are mainly structured into groups of parapatric, ecologically equivalent species. In both communities, pollinating wasp species diversity is twice that within parasite group, and the different parasite functional groups on a fig host present similar numbers of parapatric species (4 on Ficus hirta, 1-2 on F. rubiginosa). A direct correlate is that these parasitoids and cleptorasites are not host specialists, as they parasitize several host species. Such heterogeneous diversification patterns may be general. Indeed, in communities of oak galling wasps, galling species present more divergent populations through their range than their parasitoids (Stone et al., 2012). The pattern observed here could fit within the general 
scenario where parasitoids of endophytic herbivores (e.g. gallers and leaf miners) are less specialized than parasitoids of exophytic herbivores (Askew \& Shaw, 1986). Endophytic parasitoids are generally idiobionts and more subject to interspecific competition (B. A. 410 Hawkins, Askew, \& Shaw, 1990), a process which underpins our hypothesis. Another more general example is that of leaf mining insects, a group of endophytes attacked in some cases by rather generalist parasitoids whose host use better correlates to plant than host phylogeny (Ives \& Godfray, 2006; Leppänen et al., 2013; Lopez-Vaamonde, Godfray, \& Cook, 2003). The age of divergence among Valisia host species is estimated at over $10 \mathrm{Ma}$ with some subgroups splitting as recently as 2.6 Ma (Yu et al., 2019) the age of Western Palearctic cynipid wasp communities is around 3.5 Ma. The progenitor oak gall wasp community likely assembled before the expansion of oaks into from Asia around 5-7 Ma (Stone et al., 2012). The accumulation of species in these last two systems has operated over similar timescales. While climactic history clearly differs, there are strong parallels in the ecology of the parasites in both systems. These studies highlight the need for range-wide studies for understanding host specificity.

The diversity within group and among locations (beta diversity) was more than twice as high in Ficus hirta than in F. rubiginosa while the number of groups (alpha diversity) was much higher in F. rubiginosa resulting in a total of at least 17 non-pollinating wasp species

425 (Darwell \& Cook, 2017; Segar et al., 2014). A simple explanation could be that a shared factor, more limited wasp dispersal, reduces the number of species that can survive locally while facilitating geographic speciation. In agreement, alpha-diversity of fig-wasp communities has been shown to correlate with tree height and breeding system (Compton \& Hawkins, 1992). Comparative studies will allow unravelling the causal factors involved. 
The geographic stability of community structure reported here is frequent in fig-wasp communities. Indeed, there was no, or almost no, latitudinal turnover in parasite species number for 26 Ficus species in southern Africa (B. A. Hawkins \& Compton, 1992). The structure of the community associated with Ficus rubiginosa in Australia is constant throughout its range despite geographic turnover in species composition (Darwell \& Cook, 2017; Segar et al., 2014). Similarly, the communities associated with $F$. benjamina in Hainan Island and in Australia, while sharing no species, presented highly similar structures (Darwell et al., 2018). Such geographic stability suggests a role for deterministic processes in which host-plant traits determine the structure of their associated fig-wasp communities. Indeed, figwasp communities present independently evolved convergent structure across continents (Segar et al., 2013), and the complexity of fig-wasp communities in southern Africa is determined by ecological factors such as tree height rather than by phylogenetic history (Compton \& Hawkins, 1992).

\section{A generalized pattern of limited spatial turn over in community structure of plant 445}

\section{associated insects}

As for fig wasps, the structure of the communities constituted by deciduous-oak galling wasps and their parasitoids across the Western Palearctic is remarkably stable. Indeed, species turnover between refugia in Iran, the Balkan and Iberia is extremely limited (Stone et al., 2012), and this is achieved despite contrasting biogeographic patterns for the different species. However, if we accept long distance dispersal to be frequent, as documented for the oak associated communities and for fig wasps, then we may expect current genetic structure to reflect the history of the individual species, with occasional regional extinctions of some taxa followed by re-colonization, but also range-wide invasions with species replacements. Homogeneous spatial genetic structure and age of colonization within a community is not a 
prediction (Alvarez, McKey, Kjellberg, \& Hossaert-McKey, 2010). Nevertheless, stability of community structure without geographic species turnover was observed in the most extensive survey of geographic variation in tropical herbivorous insects, in the New Guinea lowlands, over distances of 500-1000 km (V. Novotny et al., 2007). Species turnover should probably be scaled relative to geographical distances, to variation in ecological conditions and to age of the examined communities.

\section{Conclusions}

Comprehensive data on geographic variation in fig wasp community structure, spatial genetic structure, and phylogenetic history is providing new insights into the ecological and evolutionary determinants of community structure and composition. In the case of F. hirta

465 fewer cleptoparasite and parasitoid species are found than obligate pollinator species. These non-pollinating fig wasps are generalist, in the sense that they can utilise several pollinator species as hosts. Furthermore, while range size varies among similar non-pollinating fig wasp species, it is generally large and non-overlapping. As the two types of parasitic wasps are non-specialists and present different geographic patterns, co-diversification is not a process shaping local and regional communities. Isolation by distance is lower in pollinators than non-pollinators. Finally, most populations of $F$. hirta are utilised by a single pollinator species along with one cleptoparasite and one parasitoid. Our results highlight the links between ecology, life history and evolutionary history in shaping community structure, patterns of genetic diversity and host specificity. Fig wasp communities are becoming a major biological model to understand the diversification of insect communities feeding on plants in the tropics, with real hopes of establishing a set of general rules. 


\section{Acknowledgements}

We thank Prof. Xia Nianhe, Peng Yanqiong, Vu Quang Nam, Tien Tran, Nong Van Duy, Zhang Xianchun (collecting permit number in Indonesia: No.1799IPH.1.02/KS.01/XI/2014), Harry Wiriadinata, Arief Hidayat, Wei Ran, Chen Wenli, Mashhor Mansor, Nora Sikin, Serena Lee (provided Singapore samples), Khin Me Aung, Chuck Cannon, Thitima 490 Tharawoot, and Liang Dan for sample collection and help in the field. This work was supported by the National Natural Science Foundation of China (31630008; 31670395), Key Special Project for Introduced Talents Team of Southern Marine Science and Engineering Guangdong Laboratory (Guangzhou) (GML2019ZD0408), the National Natural Science Foundation of China (31971568), Province Natural Science Foundation of Guangdong (c20140500001306), and the CAS President's International Fellowship Initiative (2018VBA0040). Simon Segar is grateful for departmental support from Harper Adams University. 


\section{References}

Ahmed, S., Compton, S. G., Butlin, R. K., \& Gilmartin, P. M. (2009). Wind-borne insects mediate directional pollen transfer between desert fig trees 160 kilometers apart. Proceedings of the National Academy of Sciences of the United States of America, 106(48), 20342-20347.

Alvarez, N., McKey, D., Kjellberg, F., \& Hossaert-McKey, M. (2010). Phylogeography and historical biogeography of obligate specific mutualisms. In S. Morand \& B. R. Krasnov (Eds.), The Biogeography of Host-Parasite Interactions. (pp. 31-39). Oxford: Oxford University Press.

Askew, R., \& Shaw, M. R. (1986). Parasitoid communities: Their size, structure and development. Waage, J and Greathead, D (Eds), Insect Parasitoids, 13th Symposium of Royal Entomological Society of London, 225-264. Academic Press, London: now Elsevier.

Bain, A., Borges, R. M., Chevallier, M. H., Vignes, H., Kobmoo, N., Peng, Y. Q., ... Hossaert-Mckey, M. (2016). Geographic structuring into vicariant species-pairs in a wide-ranging, high-dispersal plant-insect mutualism: The case of Ficus racemosa and its pollinating wasps and. Evolutionary Ecology, 30(4), 663-684. doi: 10.1007/s10682-016-9836-5

Belkhir, K., Borsa, P., Chikhi, L., Raufaste, N., \& Bonhomme, F. (1996). GENETIX 4.05, logiciel sous Windows TM pour la génétique des populations.

Bunnefeld, L., Hearn, J., Stone, G. N., \& Lohse, K. (2018). Whole-genome data reveal the complex history of a diverse ecological community. Proceedings of the National Academy of Sciences, 115(28), E6507-E6515. doi: 10.1073/pnas.1800334115

Butterill, P. T., \& Novotny, V. (2015). Gall-forming insects in a lowland tropical rainforest: Low species diversity in an extremely specialised guild. Ecological Entomology, 40(4), 409-419. doi: 10.1111/een.12198

Compton, S. G., Ellwood, M. D. F., Davis, A. J., \& Welch, K. (2000). The flight heights of chalcid wasps (Hymenoptera, Chalcidoidea) in a lowland Bornean rain forest: Fig wasps are the high fliers. 
Biotropica, 32(3), 515-522.

Compton, S. G., \& Hawkins, B. A. (1992). Determinants of species richness in southern African fig wasp assemblages. Oecologia, 91(1), 68-74.

Compton, S. G., Rasplus, J.-Y., \& Ware, A. B. (1994). African fig wasp parasitoid communities. In B. Hawkins \& W. Sheehan (Eds.), Parasitoid Community Ecology (pp. 323-348). Oxford: Oxford University Press.

Conchou, L., Ciminera, M., Hossaert-McKey, M., \& Kjellberg, F. (2014). The non-pollinating fig wasps associated with Ficus guianensis: Community structure and impact of the large species on the fig/pollinator mutualism. Acta Oecologica, 57(0), 28-37. doi: http://dx.doi.org/10.1016/j.actao.2013.07.004

Cook, J. M, \& Rasplus, J.-Y. (2003). Mutualists with attitude: Coevolving fig wasps and figs. Trends in Ecology \& Evolution, 18(5), 241-248.

Cook, J. M, \& Segar, S. T. (2010). Speciation in fig wasps. Ecological Entomology, 35(s1), 54-66.

Cook, James M., Reuter, C., Moore, J. C., \& West, S. A. (2017). Molecular markers reveal reproductive strategies of non-pollinating fig wasps: Molecular revelation of fig wasp behaviour. Ecological Entomology, 42(6), 689-696. doi: 10.1111/een.12433

Cruaud, A., Rønsted, N., Chantarasuwan, B., Chou, L. S., Clement, W. L., Couloux, A., ... Savolainen, V. (2012). An extreme case of plant-insect codiversification: Figs and fig-pollinating wasps. Systematic Biology, 61(6), 1029-1047. doi: 10.1093/sysbio/sys068

555 Darwell, C. T., Al-Beidh, S., \& Cook, J. M. (2014). Molecular species delimitation of a symbiotic figpollinating wasp species complex reveals extreme deviation from reciprocal partner specificity. BMC Evolutionary Biology, 14(1), 189.

Darwell, C. T., \& Cook, J. M. (2017). Cryptic diversity in a fig wasp community-morphologically differentiated species are sympatric but cryptic species are parapatric. Molecular Ecology, 
26(3), 937-950. doi: 10.1111/mec.13985 
Darwell, C. T., Segar, S. T., \& Cook, J. M. (2018). Conserved community structure and simultaneous divergence events in the fig wasps associated with Ficus benjamina in Australia and China and. BMC Ecology, 18(1), 13. doi: 10.1186/s12898-018-0167-y

Farache, F. H. A., Cruaud, A., Rasplus, J.-Y., Cerezini, M. T., Rattis, L., Kjellberg, F., \& Pereira, R. A. S. (2018). Insights into the structure of plant-insect communities: Specialism and generalism in a regional set of non-pollinating fig wasp communities. Acta Oecologica, 90(49-59).

Forister, M. L., \& Feldman, C. R. (2011). Phylogenetic cascades and the origins of tropical diversity. Biotropica, 43(3), 270-278.

Galiana, N., Hawkins, B. A., \& Montoya, J. M. (2019). The geographical variation of network structure is scale dependent: Understanding the biotic specialization of host-parasitoid networks. Ecography, 42(6), 1175-1187. doi: 10.1111/ecog.03684

Gotelli, N. J., Hart, E. M., \& Ellison, A. M. (2015). EcoSimR: Null model analysis for ecological data. doi: 10.5281/zenodo.16522

Harrison, R. D. (2003). Fig wasp dispersal and the stability of a keystone plant resource in Borneo. Proceedings of the Royal Society of London Series B: Biological Sciences, 270, S76-S79.

Harrison, R. D., \& Rasplus, J. Y. (2006). Dispersal of fig pollinators in Asian tropical rain forests. Journal of Tropical Ecology, 22(06), 631. doi: 10.1017/S0266467406003488

Hawkins, B. A. (1994). Pattern and process in host-parasitoid interactions. Cambridge: Cambridge University Press.

Hawkins, B. A., Askew, R. R., \& Shaw, M. A. (1990). Influences of host feeding-niche and foodplant type on generalist and specialist parasitoids. Ecological Entomology, 15(3), 275-280.

Hawkins, B. A., \& Compton, S. G. (1992). African fig wasp communities-Undersaturation and latitudinal gradients in species richness. Journal of Animal Ecology, 61(2), 361-372.

Hawkins, B. A., Cornell, H. V., \& Hochberg, M. E. (1997). Predators, parasitoids, and pathogens as mortality agents in phytophagous insect populations. Ecology, 78(7), 2145-2152. doi: 


\subsection{0/0012-9658(1997)078[2145:PPAPAM]2.0.CO;2}

Hernández-López, A., Rougerie, R., Augustin, S., Lees, D. C., Tomov, R., Kenis, M., ... LópezVaamonde, C. (2012). Host tracking or cryptic adaptation? Phylogeography of Pediobius saulius (Hymenoptera, Eulophidae), a parasitoid of the highly invasive horse-chestnut leafminer: Parasitoid host races. Evolutionary Applications, 5(3), 256-269. doi: 10.1111/j.1752-4571.2011.00220.x

Hrcek, J., \& Godfray, H. C. J. (2015). What do molecular methods bring to host-parasitoid food webs? Trends in Parasitology, 31, 30-35.

Hrcek, J., Miller, S. E., Whitfield, J. B., Shima, H., \& Novotny, V. (2013). Parasitism rate, parasitoid community composition and host specificity on exposed and semi-concealed caterpillars from a tropical rainforest. Oecologia, 173(2), 521-532. doi: 10.1007/s00442-013-2619-6

Ives, A. R., \& Godfray, H. C. J. (2006). Phylogenetic analysis of trophic associations. American Naturalist, 168, 1-14.

Joseph, J. K. (1958). Recherches sur les chalcidiens, Blastophaga psenes (L.) et Phylotrypesis caricae (10), 197-260.

Jousselin, E., van Noort, S., Berry, V., Rasplus, J.-Y., Ronsted, N., Erasmus, C. J., \& Greef., J. M. (2008). One fig to bind them all: Host conservatism in a fig wasp community unraveled by cospeciation analyses among pollinating and nonpollinating fig wasps. Evolution, 62, 17771797. doi: doi:10.1111/j.1558-5646.2008.00406.x

Kjellberg, F., \& Proffit, M. (2016). Tracking the elusive history of diversification in plant-herbivorous insect-parasitoid food webs: Insights from figs and fig wasps. Molecular Ecology, 25(4), 843845. doi: $10.1111 / \mathrm{mec} .13533$

Lapchin, L. (2002). Host-parasitoid association and diffuse coevolution: When to be a generalist? The American Naturalist, 160(2), 245-254. 
Leppänen, S. A., Altenhofer, E., Liston, A. D., \& Nyman, T. (2013). Ecological versus phylogenetic determinants of trophic associations in a plant-leafminer-parasitoid food web. Evolution, 67, 1493-1502. doi: 10.1111/evo.12028

Lewis, O. T., Memmott, J., Lasalle, J., Lyal, C. H. C., Whitefoord, C., \& Godfray, H. C. J. (2002). Structure of a diverse tropical forest insect-parasitoid community. Journal of Animal Ecology, 71(5), 855-873. doi: 10.1046/j.1365-2656.2002.00651.x

Li, Y., Zhou, X., Feng, G., Hu, H., Niu, L., Hebert, P. D. N., \& Huang, D. (2010). COI and ITS2 sequences delimit species, reveal cryptic taxa and host specificity of fig-associated Sycophila (Hymenoptera, Eurytomidae). Molecular Ecology Resources, 10(1), 31-40. doi: 10.1111/j.1755-0998.2009.02671.x

Lopez-Vaamonde, C., Godfray, H. C. J., \& Cook, J. M. (2003). Evolutionary dynamics of host-plant use in a genus of leaf-mining moths. Evolution, 57(8), 1804-1821.

Mayr, G. (1885). Fig insecten. Verhandlungen Der Zoologische Botanische Gesellschaft Wien (B), (35), 147-250.

McLeish, M. J., Beukman, G., van Noort, S., \& Wossler, T. C. (2012). Host-plant species conservatism and ecology of a parasitoid fig wasp genus (Chalcidoidea; Sycoryctinae; Arachonia). PLoS ONE, 7(9), e44804. doi: 10.1371/journal.pone.0044804

Moe, A. M., Clement, W., \& Weiblen, G. D. (2012). Rapid evolution of pollinator-mediated plant reproductive isolation. In R. S. Singh, X. Jianping, \& R. Kulathinal (Eds.), Rapidly Evolving Genes and Genetic Systems (p. 312). Oxford, Oxfordshire, UK: Oxford University Press.

Molbo, D. (2003). Cryptic species of fig-pollinating wasps: Implications for the evolution of the figwasp mutualism, sex allocation, and precision of adaptation. Proceedings of the National Academy of Sciences of the United States of America, 100(10), 5867-5872.

Nair, P. B., Abdurahiman, U. C., \& Joseph, J. M. (1981). Two new Torymidae (Hymenoptera, 
Nicholls, J. A., Schönrogge, K., Preuss, S., \& Stone, G. N. (2018). Partitioning of herbivore hosts across time and food plants promotes diversification in the Megastigmus dorsalis oak gall parasitoid complex. Ecology and Evolution, 8(2), 1300-1315. doi: 10.1002/ece3.3712 Novotny, V., Miller, S. E., Hulcr, J., Drew, R. A. I., Basset, Y., Janda, M., ... Auga, J. (2007). Low beta diversity of herbivorous insects in tropical forests. Nature, 448(7154), 692-695.

Novotny, Vojtech, Miller, S. E., Hrcek, J., Baje, L., Basset, Y., Lewis, O. T., ... Weiblen, G. D. (2012). Insects on plants: Explaining the paradox of low diversity within specialist herbivore guilds. The American Naturalist, 179(3), 351-362. doi: 10.1086/664082

Peakall, P., \& Smouse, P. E. (2006). GENALEX 6: Genetic analysis in Excel. Population genetic software for teaching and research. Molecular Ecology Notes, 6, 288-295.

Price, P. W. (2002). Resource-driven terrestrial interaction webs. Ecological Research, 17(2), 241247.

Pritchard, J. K., Stephens, M., \& Donnelly, P. (2000). Inference of population structure using multilocus genotype data. Genetics, 155, 945-959. Diversification and spatial structuring in the mutualism between Ficus septica and its pollinating wasps in insular South East Asia. BMC Evolutionary Biology, 17(1), 207. doi: $10.1186 / \mathrm{s} 12862-017-1034-8$

Rousset, F. (1997). Genetic differentiation and estimation of gene flow from F-statistics under isolation by distance. Genetics, 145(4), 1219-1228.

Segar, S. T., Dunn, D. W., Darwell, C. T., \& Cook, J. M. (2014). How to be a fig wasp down under: The diversity and structure of an Australian fig wasp community. Acta Oecologica, 15, 17-27.

Segar, S. T., Fayle, T. M., Srivastava, D. S., Lewinsohn, T. M., Lewis, O. T., Novotny, V., ... Maunsell, S. 
C. (2020). The role of evolution in shaping ecological networks. Trends in Ecology \&

Evolution, 35(5), 454-466. doi: 10.1016/j.tree.2020.01.004 
Segar, S. T., Lopez-Vaamonde, C., Rasplus, J.-Y., \& Cook, J. M. (2012). The global phylogeny of the subfamily Sycoryctinae (Pteromalidae): Parasites of an obligate mutualism. Molecular Phylogenetics and Evolution, 65, 116-125.

Segar, S. T., Pereira, R. A. S., Compton, S. G., \& Cook, J. M. (2013). Convergent evolution of 665 multitrophic community structure over three continents. Ecology Letters, 16(12), 14361445.

Smith, M. A., Rodriguez, J. J., Whitfield, J. B., Deans, A. R., Janzen, D. H., Hallwachs, W., \& Hebert, P. D. N. (2008). Extreme diversity of tropical parasitoid wasps exposed by iterative integration of natural history, DNA barcoding, morphology, and collections. Proceedings of the National Academy of Sciences of the United States of America, 105(34), 12359.

Smith, M. A., Woodley, N. E., Janzen, D. H., Hallwachs, W., \& Hebert, P. D. N. (2006). DNA barcodes reveal cryptic host-specificity within the presumed polyphagous members of a genus of parasitoid flies (Diptera: Tachinidae). Proceedings of the National Academy of Sciences, 103(10), 3657-3662. doi: 10.1073/pnas.0511318103 Faster speciation of fig-wasps than their host figs leads to decoupled speciation dynamics: Snapshots across the speciation continuum. Molecular Ecology, 28(17), 3958-3976. doi: $10.1111 /$ mec.15190

Sow, A., Brévault, T., Benoit, L., Chapuis, M.-P., Galan, M., Coeur d’acier, A., ... Haran, J. (2019). Deciphering host-parasitoid interactions and parasitism rates of crop pests using DNA metabarcoding. Scientific Reports, 9(1), 3646. doi: 10.1038/s41598-019-40243-z

Stireman, J. O., Nason, J. D., Heard, S. B., \& Seehawer, J. M. (2006). Cascading host-associated genetic differentiation in parasitoids of phytophagous insects. Proceedings of the Royal Society B: Biological Sciences, 273(1586), 523-530. 
Stone, G. N., Lohse, K., Nicholls, J. A., Fuentes-Utrilla, P., Sinclair, F., Schönrogge, K., ... Hickerson, M.

J. (2012). Reconstructing community assembly in time and space reveals enemy escape in a western palearctic insect community. Current Biology, 22(6), 532-537.

Sutton, T. L., Riegler, M., \& Cook, J. M. (2016). One step ahead: A parasitoid disperses farther and forms a wider geographic population than its fig wasp host. Molecular Ecology, 25(4), 882894. doi: $10.1111 / \mathrm{mec} .13445$

Tamura, K., Stecher, G., Peterson, D., Filipski, A., \& Kumar, S. (2013). MEGA6: Molecular evolutionary genetics analysis version 6.0. Molecular Biology and Evolution, 30(12), 2725-2729.

Thompson, J. N. (1994). The Coevolutionary Process. Chicago: The University of Chicago Press.

Tian, E., Nason, J. D., Machado, C. A., Zheng, L., Yu, H., \& Kjellberg, F. (2015). Lack of genetic isolation by distance, similar genetic structuring but different demographic histories in a figpollinating wasp mutualism. Molecular Ecology, 24(23), 5976-5991. doi: 10.1111/mec.13438

Van Veen, F. J. F., Müller, C. B., Pell, J. K., \& Godfray, H. C. J. (2008). Food web structure of three guilds of natural enemies: Predators, parasitoids and pathogens of aphids. Journal of Animal Ecology, 77(1), 191-200. doi: 10.1111/j.1365-2656.2007.01325.x

Venkateswaran, V., Shrivastava, A., Kumble, A. L. K., \& Borges, R. M. (2017). Life-history strategy, resource dispersion and phylogenetic associations shape dispersal of a fig wasp community. Movement Ecology, 5(1), 25. doi: 10.1186/s40462-017-0117-x

Weiblen, G. D., \& Bush, G. L. (2002). Speciation in fig pollinators and parasites. Molecular Ecology, 11(8), 1573-1578.

Yu, H., Liang, D., Tian, E., Zheng, L., \& Kjellberg, F. (2018). Plant geographic phenotypic variation drives diversification in its associated community of a phytophagous insect and its parasitoids. BMC Evolutionary Biology, 18(1), 134. doi: 10.1186/s12862-018-1239-5

Yu, H., Tian, E., Zheng, L., Deng, X., Cheng, Y., Chen, L., ... Kjellberg, F. (2019). Multiple parapatric pollinators have radiated across a continental fig tree displaying clinal genetic variation. Molecular Ecology, 28, 2391-2405. doi: doi.org/10.1111/mec.15046 


\section{Data Accessibility}

Microsatellite genotype data for all individuals of Philotrypesis and Syocryctini are archived in the Dryad Digital Repository at http://datadryad.org, doi: 10.5061/dryad.5x69p8d0x.

YH designed research, collected samples, analyzed data and co-wrote the manuscript. CLF analyzed data. STS co-wrote the manuscript. FK contributed to data analyses and co-wrote the manuscript. DXX performed laboratory work and analyzed data. EWT performed laboratory work. DYZ designed research. WT collected samples in Thailand.

\section{Figure legends}

Fig. 1. Maximum likelihood phylogenetic tree based on Cytb sequences. Genus Philotrypesis belongs to the monophyletic tribe Phylotrypesini while genera Sycoryctes and Sycoscapter belong to the monophyletic tribe Sycoryctini.

Fig. 2. Cumulative distribution of Kimura pairwise genetic distances (K2P) for Cytb for

Philotrypesis, Sycoryctini and Valisia wasps associated with Ficus hirta. There is a marked barcoding gap between clades in the Sycoryctini. Philotrypesis clades are less differentiated, and the barcoding gap is less marked. In Valisia, there is almost no barcoding gap due to the presence of two complexes of closely related species.

Fig. 3. Geographic distribution of the three sets of fig wasps associated with Ficus hirta and 735 genetic variation of the plant. Locations indicated with coloured lettering are those for which species assignment was based on SSR genotypes only. Philotrypesis are assumed to be cleptoparasites of Valisia, Sycoscapter and Sycoryctes are assumed to be parasitoids of Valisia. Valisia are the pollinators of Ficus hirta and feed on galled plant tissue. For the plant, genetic variation is clinal and is illustrated by percentage of assignment to two extreme 740 gene pools.

Table 1. Results of coocuurence analysis between i) species within each wasp genus at each site and ii) the two main parasite wasp genera and each Valisia pollinator species. SES: standardised effect size.

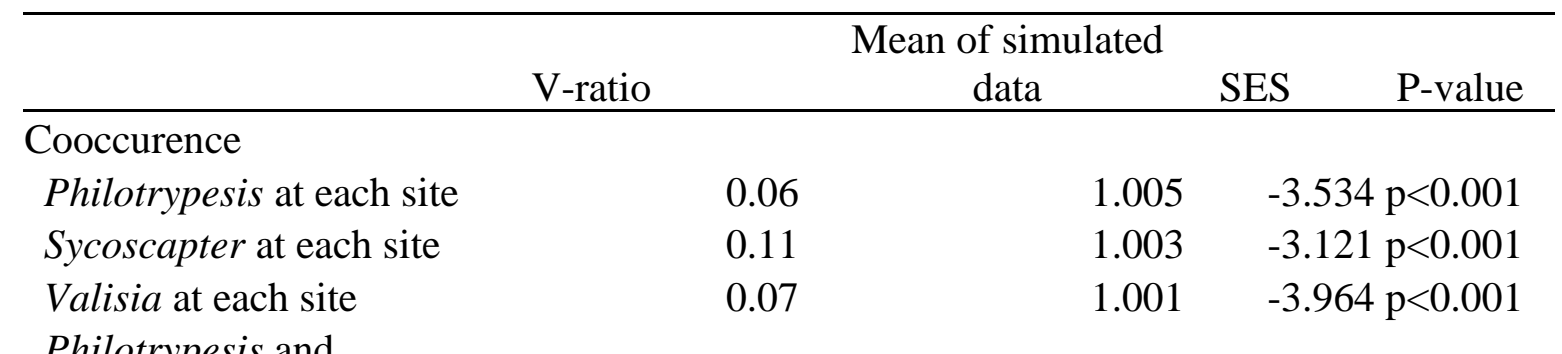

Philotrypesis and 


\begin{tabular}{lrrrrl} 
Sycoscapter & \multicolumn{2}{c}{0.33} & \multicolumn{2}{c}{1.022} & $-0.837 \mathrm{~ns}$ \\
\hline $\begin{array}{l}\text { Czekanowski niche } \\
\text { overlap }\end{array}$ & \multicolumn{2}{c}{$\begin{array}{c}\text { Czekanowski } \\
\text { index }\end{array}$} & $\begin{array}{r}\text { Mean of simulated } \\
\text { data }\end{array}$ & SES & P-value \\
\hline $\begin{array}{l}\text { Philotrypesis } \text { and Valisia } \\
\text { Sycoscapter and Valisia }\end{array}$ & 0.22 & 0.164 & 0.727 & $\mathrm{~ns}$ \\
& 0.11 & 0.145 & -0.305 & $\mathrm{~ns}$ \\
\hline
\end{tabular}

\section{Supporting information}

Additional Supporting Information may be found in the online version of this article: 


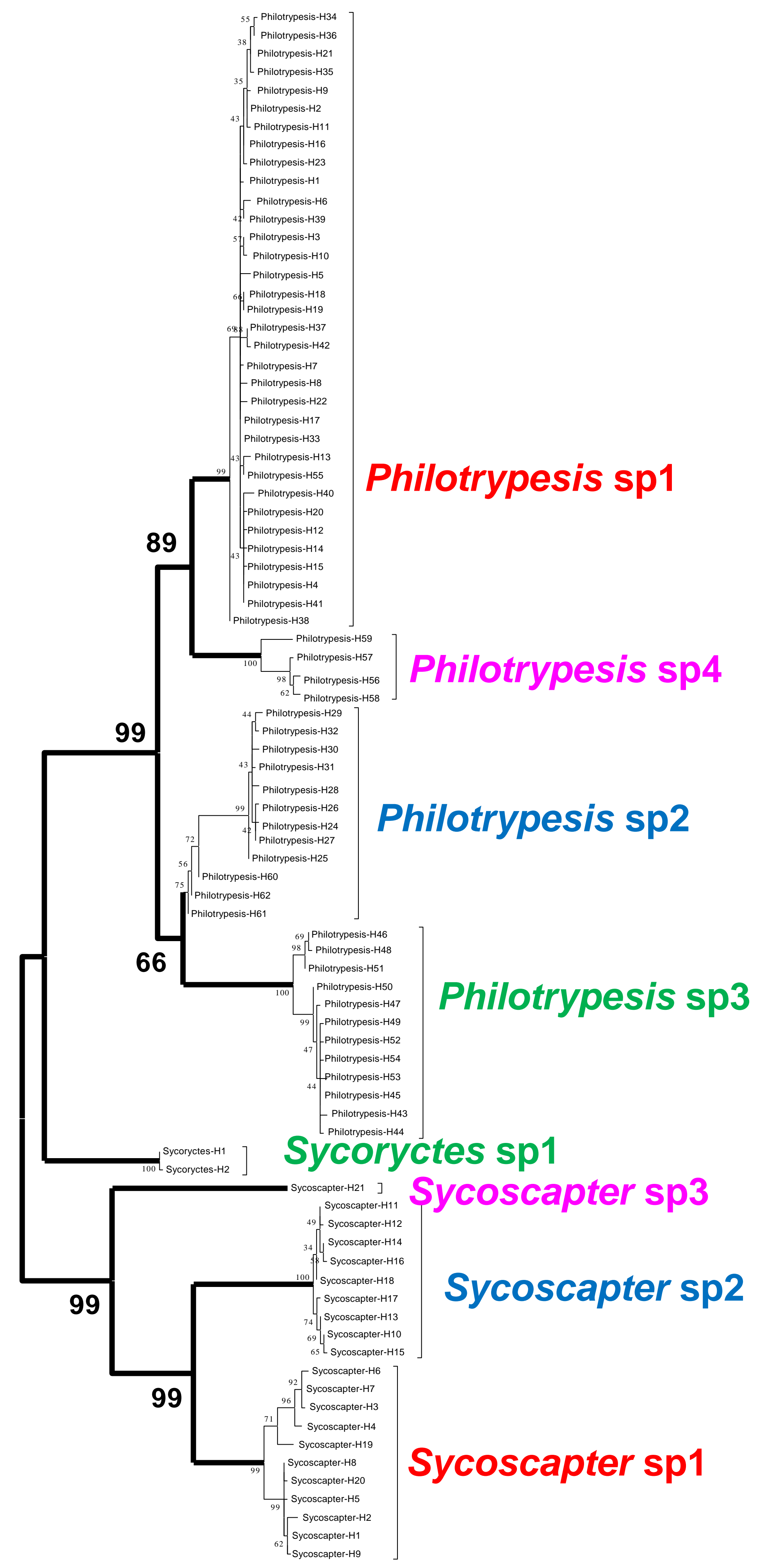




\section{Philotrypesis Cytb}

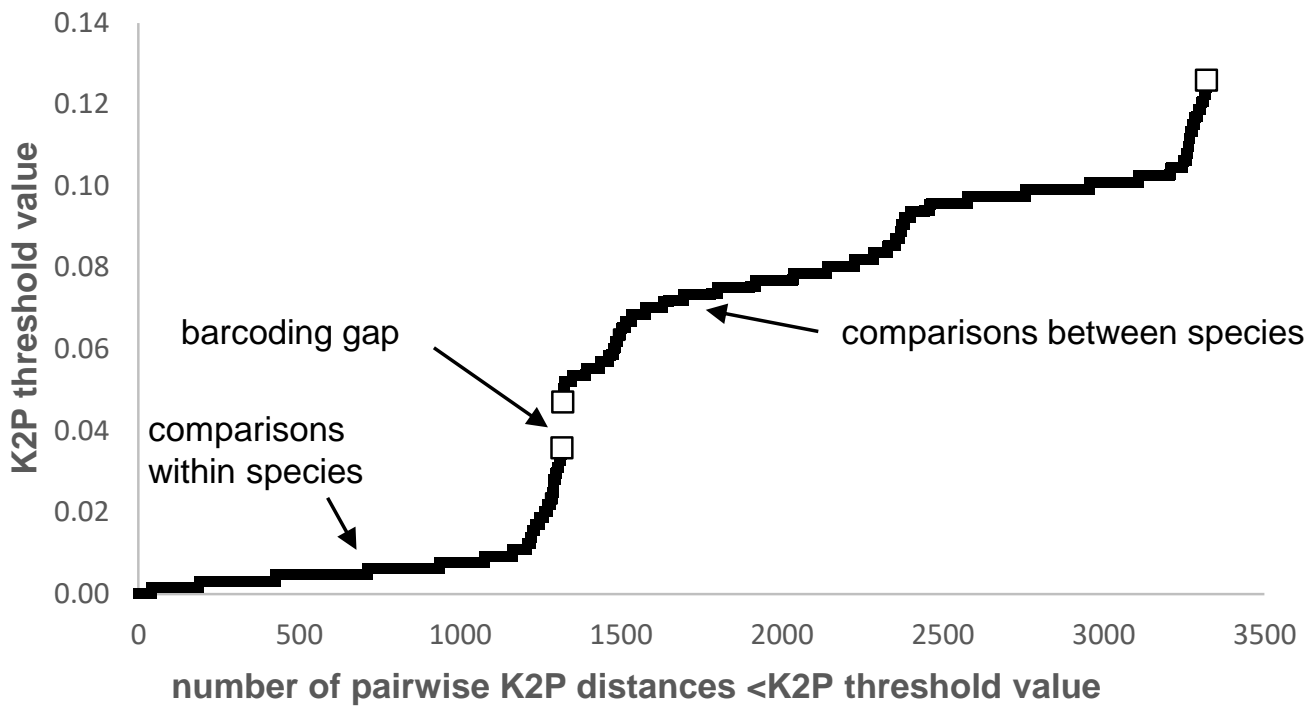

Sycoryctini Cytb

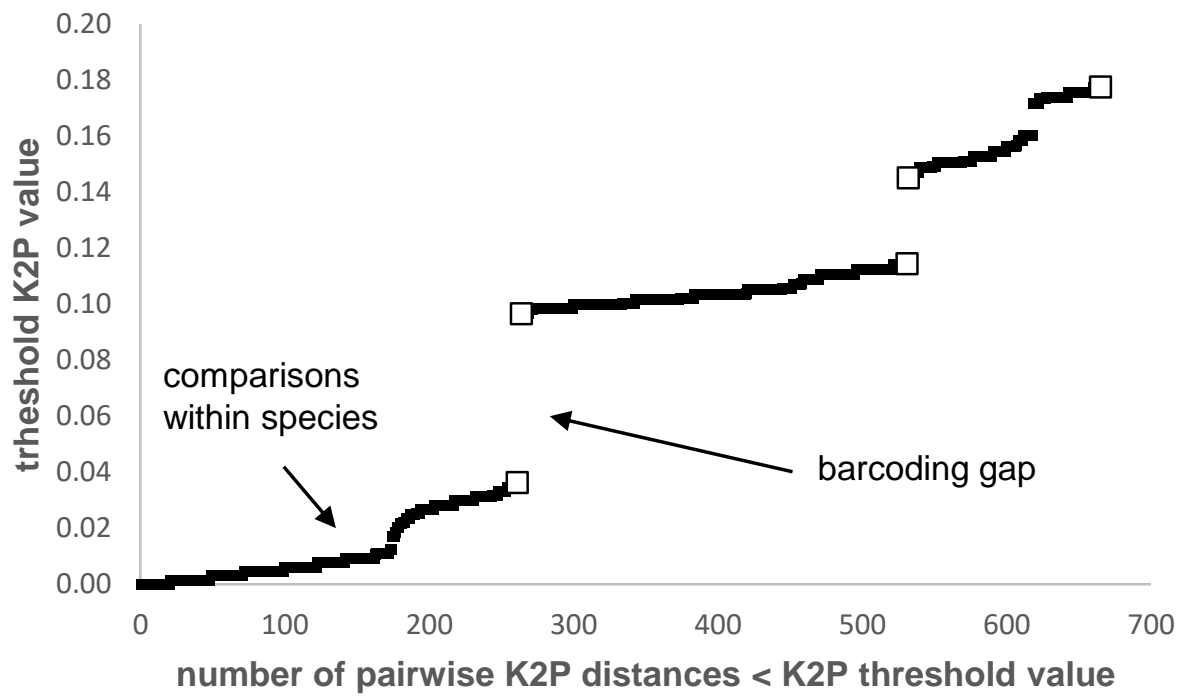



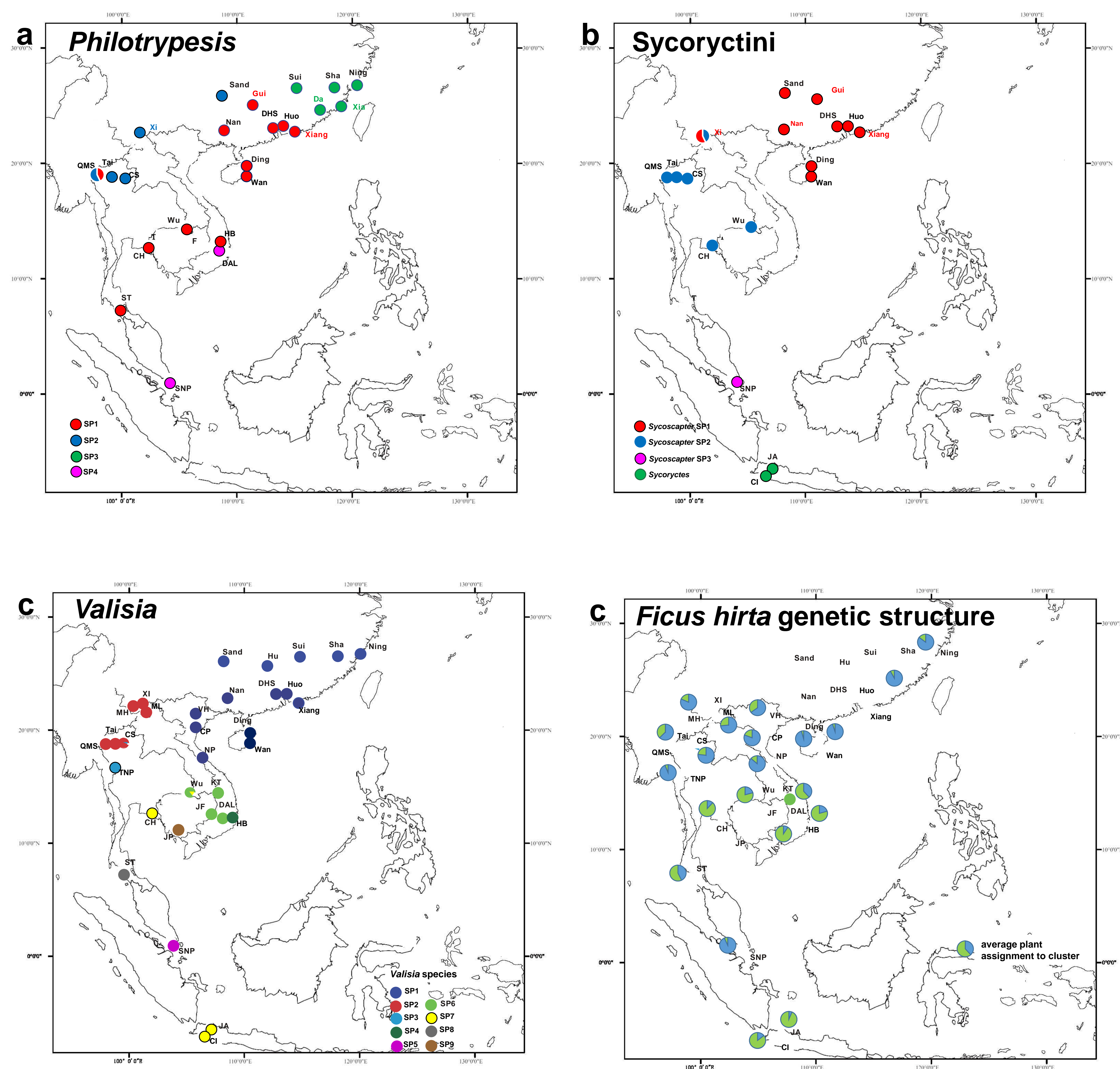